\title{
Choosing a Future Shoreline for the San Francisco Bay: Strategic Coastal Adaptation Insights from Cost Estimation
}

\author{
Daniella Hirschfeld * (D) and Kristina E. Hill \\ College of Environmental Design, University of California Berkeley, Berkeley, CA 94720, USA; \\ kzhill@berkeley.edu \\ * Correspondence: daniellah@berkeley.edu; Tel.: +1-510-642-2962
}

Received: 31 May 2017; Accepted: 26 August 2017; Published: 4 September 2017

\begin{abstract}
In metropolitan regions made up of multiple independent jurisdictions, adaptation to increased coastal flooding due to sea level rise requires coordinated strategic planning of the physical and organizational approaches to be adopted. Here, we explore a flexible method for estimating physical adaptation costs along the San Francisco Bay shoreline. Our goal is to identify uncertainties that can hinder cooperation and decision-making. We categorized shoreline data, estimated the height of exceedance for sea level rise scenarios, and developed a set of unit costs for raising current infrastructure to meet future water levels. Using these cost estimates, we explored critical strategic planning questions, including shoreline positions, design heights, and infrastructure types. For shoreline position, we found that while the shortest line is in fact the least costly, building the future shoreline at today's transition from saltwater to freshwater vegetation is similar in cost but allows for the added possibility of conserving saltwater wetlands. Regulations requiring a specific infrastructure design height above the water level had a large impact on physical construction costs, increasing them by as much as $200 \%$. Finally, our results show that the costs of raising existing walls may represent $70 \%$ to $90 \%$ of the total regional costs, suggesting that a shift to earthen terraces and levees will reduce adaptation costs significantly.
\end{abstract}

Keywords: sea level rise; coastal flooding; cost estimation; adaptation; coastal realignment; climate change; coastal planning; coastal management; San Francisco Bay; levees; seawalls

\section{Introduction}

Flooding and its associated consequences for human development are a major threat to coastal communities [1,2]. These impacts are exacerbated by human development in flood-prone areas $[3,4]$. Scientific evidence shows that climate change is intensifying these risks by accelerating relative sea level rise, elevating water tables in coastal areas, and increasing the incidence of extreme precipitation [5-7]. Estuaries provide a uniquely valuable setting for human settlement, but these urban regions are very vulnerable to sea level rise. Specifically, sea level rise in estuaries will result in landward movement of both the average and storm-driven high water lines; landward migration of the salinity gradient in surface and groundwater; changes in sediment transport and deposition; and coastal "squeeze", resulting in a loss of inter-tidal wetlands as well as damage to conventional urban districts and infrastructure $[4,8]$. Globally, some urban estuaries are already grappling with these threats, including the Thames Estuary [9] and the Wash region of the United Kingdom [10], the Elbe in Germany [11], and the Chesapeake Bay in the United States [12]. The San Francisco Bay urban region is also constructed in an estuary context, and presents an opportunity to gain insights about various physical adaptation strategies for shoreline realignment by estimating their adaptation costs and systematically 
varying key drivers of those costs. It is likely that some of these strategic insights will be applicable to other urban estuary regions.

Recent research shows that in the San Francisco Bay area, increased urban flooding and wetland habitat loss are among the greatest concerns. Currently, there are 140,000 people at risk from a 1 percent chance flood (commonly referred to as a 100 year flood), and with $1.4 \mathrm{~m}$ of sea level rise this number increases to 270,000 [13]. Estimates suggest that without adaptation actions, the cost of the impacts to buildings alone would be $\$ 49$ billion from a $1 \mathrm{~m}$ rise in sea level under a 1 percent chance storm [14]. The current projections for marsh habitat along the Bay edge are similarly dramatic. Model projections suggest that sea level rise will produce significant losses of high marsh, which is particularly valuable habitat in the region [15]. In an effort to address these threats, the State of California adopted a new law to require the incorporation of climate change into local planning [16], and is in the process of updating its guidance to local communities. As part of the State's process, the California Ocean Protection Council Science Advisory Team released a report indicating that planners should consider up to $3 \mathrm{~m}$ of sea level rise by 2100 [17]. This report is based on the probabilistic assessment approach of Kopp et al. [18].

Addressing the threats of climate change will require complex system-based approaches that allow decision-makers to gain a strategic understanding of relationships between environmental trends and adaptation pathways $[19,20]$. Adaptation planning guidance calls for the need to address critical strategic questions [21]. For example, thresholds of change in system states may be used as decision points that initiate the shift from one adaptation pathway to another pathway [9]. Similarly, a vulnerability assessment could trigger further analysis and ultimately a change to a set of adaptation actions [22].

Despite this need, certain key planning questions remain unanswered for developed estuaries such as the San Francisco Bay. In particular, while it is clear that the shoreline position will tend to move inland unless humans intervene with new infrastructure, it is not clear what variables planners should use in making shoreline realignment decisions that maximize the benefits of investments in walls, levees, dunes, and wetlands. A recent survey of local government officials identified the need for cost benefit analysis guidance to help them adapt to climate change [23]. Efforts underway in the San Francisco Bay area suggest that raising existing structures is likely to be the most common response to current and predicted flooding [24,25].

In this study, we attempt to answer the question: how do different aspects of a cost estimate for coastal protective infrastructure (including earthen levees, concrete walls, and wetlands) reveal strategic opportunities for adaptation? We specifically explored physical, economic, and regulatory issues related to the adaptation costs for such infrastructure.

In Section 2, we provide details on the data and methods used in our analysis. Section 3 presents our results for the entire San Francisco Bay Area, with a focus on identifying the cost estimates for specific types of coastal infrastructure. In Section 4, we present a discussion of these results as they relate to strategic planning questions and propose further analysis. In Section 5, we provide key conclusions from our work.

\section{Materials and Methods}

The first challenge of describing a regional shoreline is the selection of categories that organize the diversity of existing conditions in a way that is useful to adaptation decision-making. Our research is guided by the analytical framework originally presented in an earlier paper by Hill, which is summarized in Figure 1 [26]. This framework was derived from concepts related to evolutionary landscapes. Shorelines are categorized as either landforms or walls, and either static or dynamic. The typology emphasizes transformability, in terms of the feasibility of raising the infrastructure over time, and the potential for a coastal infrastructure type to provide multiple benefits. For example, the typology treats walls as single-purpose structures that do not provide multiple benefits, such as recreation, wildlife habitat, or other ecosystem services. We use this typology to describe the current 
condition of the San Francisco Bay Edge, and to assess the potential costs of adapting to future sea level rise threats.

Our initial observation, from a review of the currently planned and built projects in the San Francisco Bay region, is that the legal, economic, and political challenges of land use change will drive public agencies to respond by seeking to raise existing shore zone structures. Therefore, we designed our cost estimation method to calculate the physical project costs associated with raising the height of existing structures at various positions within the shore zone.

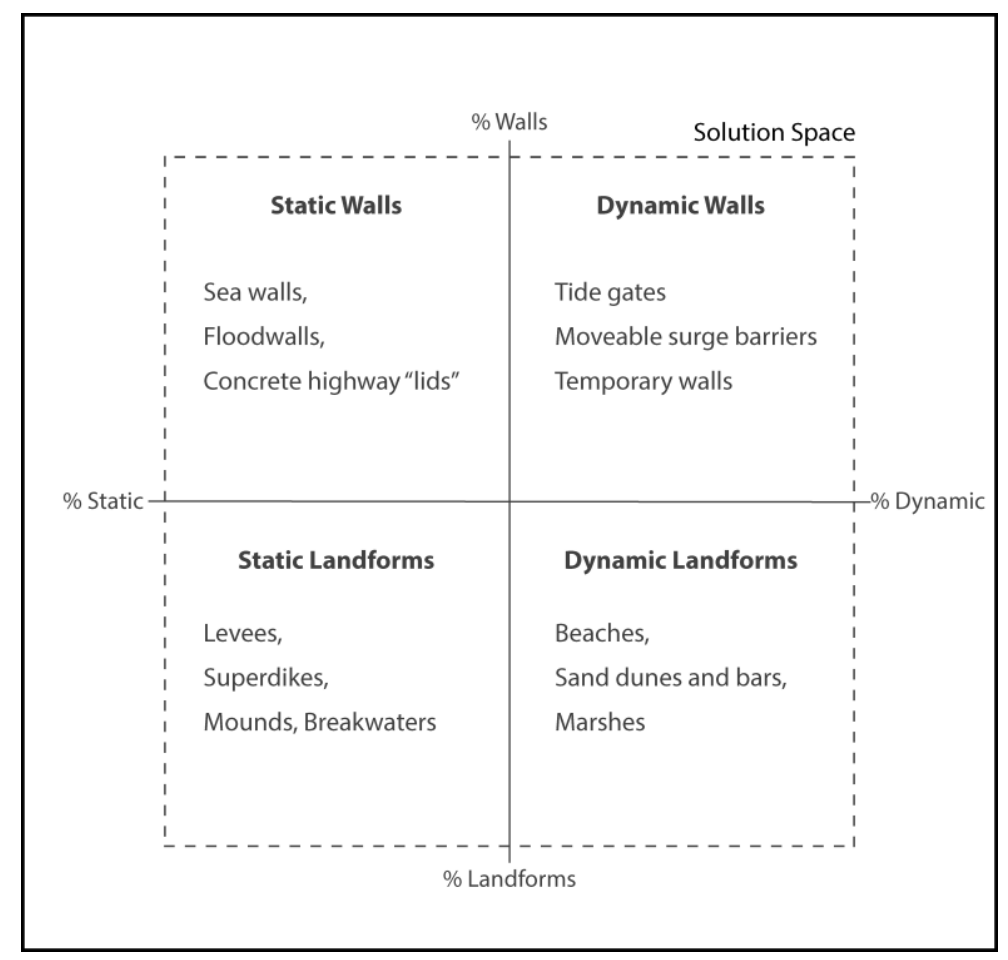

Figure 1. This four-quadrant diagram presents a typology of coastal protective shoreline structures [26]. The vertical axis is defined by the percentage of shoreline that is wall, versus the shoreline that is built with loose materials, such as sand and gravel (landform). The horizontal axis is defined by the percentage of shoreline that is dynamic (able to move, mechanically or by natural processes) versus static (fixed in position). We used this typology in our study because it allows us to differentiate among coastal structures by their approximate initial construction cost, the cost of raising the structures over time, and the variety of ecosystem services they can offer. Structures in the upper right quadrant are typically the most expensive, and structures in the lower right can offer the widest range of services.

\subsection{Data Sources}

Our analysis is based on the following two groups of data: (1) shore zone conditions and future sea level rise projections, and (2) cost estimation data. Three individual data sets, which are publically available, underlie our characterizations of the shore zone and its inundation under different sea level rise scenarios. The first dataset is a geographic information system (GIS) vector-based inventory of shoreline infrastructure along the San Francisco Bay, developed by the San Francisco Estuary Institute (SFEI) [27]. This dataset contains over 169,000 30-m line segments of linear shore structures (berms, levees, walls, etc.) that occur between mean higher high water (MHHW) and an elevation of $3 \mathrm{~m}$ above MHHW (NAVD88). These line segments include complex embayment shapes, resulting in large variations in the measured length of the Bay shoreline. For each 30-m line segment, the dataset describes four characteristics: the type of coastal structure, whether it is accredited as a protective structure, whether it is fronted by natural features (i.e., wetlands and beaches), and its current elevation relative to NAVD88. 
SFEI also developed the second dataset [28]. This is a vector-based GIS inventory of aquatic features called the Bay Area Aquatic Resource Inventory (BAARI). It includes features such as wetlands, open water, and riparian areas.

The third dataset [29] is a product of the Coastal Storm Modeling System (CoSMoS) [30], developed at the US Geological Survey (USGS). Staff at the regional flood-mapping project by Point Blue, called Our Coast, Our Future (OCOF) (http:/ / www.ourcoastourfuture.org), provided the data. This dataset provides water heights relative to NAVD88 under 40 different scenarios: 4 storm surge (mean water level, annual high water level (i.e., King Tide), and 20 year and 100 year storm-driven water levels) and 10 sea level rise scenarios (0-200 in increments of 25 and one extreme scenario of $500 \mathrm{~cm}$ ).

The second group of datasets we used allowed us to develop a regional estimate of raising coastal protective infrastructure. First, we developed a database of unit costs after an extensive review of the costs of engineered structures relevant to the San Francisco Bay region, which is summarized in Table 1. Due to limited data, we do not present cost estimates for dynamic landforms, such as wetlands, or dynamic walls, such as tide gates. Next, we created a dataset of parcel-scale land costs, collected using a web data-scraping method developed by Chris Muir [31] for use with online real-estate data (https:/ / www.zillow.com/). This method enabled us to download all of the data for the San Francisco Bay Area. All of our data can be accessed as described in Section 2.3.

Table 1. Sources and range of associated unit costs converted to thousands of 2016 USD\$.

\begin{tabular}{ccc}
\hline $\begin{array}{c}\text { Cost Range: Thousands of 2016 \$ } \\
\text { (per Linear Kilometer per Meter } \\
\text { of Elevation) }\end{array}$ & Design Type & Study Type and Source \\
$\$ 5.3-\$ 13.2$ & Landform & $\begin{array}{c}\text { SF Bay: Engineering Study } \\
\text { (USACE, 2015) }\end{array}$ \\
\hline$\$ 3.9-\$ 12.4$ & Landform & $\begin{array}{c}\text { Academic Publication from } \\
\text { Planning Work (Jonkman, 2013) }\end{array}$ \\
\hline$\$ 2.5-\$ 5.5$ & Landform & $\begin{array}{c}\text { SF Bay: Technical Report } \\
\text { (Lowe, 2013) }\end{array}$ \\
\hline $0.400-\$ 33.0$ & Wall & $\begin{array}{c}\text { International Technical Report } \\
\text { (Linham and Nicholls 2010) }\end{array}$ \\
\hline$\$ 5.8-\$ 18.3$ & Wall & $\begin{array}{c}\text { Academic Publication from } \\
\text { Planning Work (Jonkman, 2013) }\end{array}$ \\
\hline $24.5-\$ 495.5$ & Wall & $\begin{array}{c}\text { SF Bay: Engineering Study } \\
\text { (GHD-GTC Joint Venture, 2016) }\end{array}$ \\
\hline
\end{tabular}

\subsection{Shore Zone and Shoreline Positions, Sea Level Rise, and Cost Assessments}

In this first section of our study, we sought to determine where sea level rise will likely cause saltwater flooding, how much higher the existing coastal structures would have to be to prevent exceedance by rising water levels, and how much it might cost to raise the existing structures around the entire San Francisco Bay edge. We identified three baseline scenarios of shoreline re-alignment for the sake of making cost comparisons.

In the shore zone and sea level rise assessment portion of our work, we took three specific steps. First, we used the reclassification scheme shown in Table 2 to align the shoreline data from SFEI to our shoreline typology. Additionally, we used Google Earth and site visits to identify small walls not previously detected by SFEI. Second, we conducted a rapid assessment of water exceedance levels by calculating the difference in height between the floodwater and the structure. We subtracted the height of every shoreline segment in the SFEI data from the USGS CoSMoS model's projected future water levels. In the third step, we generated in GIS three potential shoreline alignments for cost comparison. The most bayward line, referred to here as "Shoreline A", was mapped using SFEI's 
shoreline infrastructure data. We used the "Bayshore_Defense" category, with the values "First line of shoreline defense" or "Wetland on Bay shore" to designate "Shoreline A". We designated the other two shorelines using an intersection of SFEI's shoreline infrastructure data and the BAARI data to distinguish the saltwater and freshwater habitat zones [28]. The shoreline referred to as "Shoreline B" uses SFEI's mapping of saltwater habitat. The shoreline referred to as "Shoreline C" is the most landward of the three we designated, and is located on the landward side of freshwater wetland habitat as mapped by SFEI.

Table 2. Reclassification scheme used to match SFEI data to our analysis framework.

\begin{tabular}{ccc}
\hline SFEI Class & Landform or Wall & Static or Dynamic \\
\hline Berm & Landform & Static \\
Channel or opening & Landform & Static \\
Embankment & Landform & Static \\
Engineered Levee & Landform & Static \\
Shoreline Protection Structure & Landform & Static \\
Natural Shoreline & Landform & Dynamic \\
Wetland & Landform & Dynamic \\
Floodwall & Wall & Static \\
Transportation Structure & Wall & Static \\
Water control structure & Wall & Dynamic \\
\hline
\end{tabular}

${ }_{1}^{1}$ This class included some smaller walls that we reclassified based on Google Earth and site visits.

Next, we calculated potential costs based on our review of unit costs specific to projects in the San Francisco Bay Area, and supplemented these data with cost calculations from the literature where needed. In Table 1, we show the range of unit costs for the two different protective infrastructure types considered in this project: landforms and walls. In this table, we present the information from five different technical and academic publications converted into the same units: thousands of 2016 USD\$ for each linear kilometer, and for each meter of raised infrastructure height [32-36].

Using this information, we compared four different approaches to calculating an approximate cost of raising the existing coastal structures: (1) simple without parcel costs, (2) simple with parcel costs, (3) complex without parcel costs, and (4) complex with parcel costs. The "simple" approaches (\#1 and \#2) used a linear relationship when calculating the cost of raising the height of a levee or a wall. Based on the work of Jonkman et al. [33], we anticipate that the size of levees will increase approximately linearly for relatively low levels of sea level rise $(0.5-1.5 \mathrm{~m})$, as shown in Figure 2 and Table 3. However, as levee height is raised beyond $1.5 \mathrm{~m}$, the relationship between height and cost is influenced more by the volume of the material in the levee. In our "complex" cost estimation approaches (\#3 and \#4), we applied a levee-growth cost factor that incorporates the geometric component of levee size, as shown in Table 3. In Approaches 3 and 4, we also used a more complex approach for estimating wall costs that incorporates the additional requirements of a seismically active region. We assumed that walls could be retrofitted if they need to be raised $0.5 \mathrm{~m}$ or less. Beyond $0.5 \mathrm{~m}$ of additional height, we assumed that the loadings on the wall would require it to be rebuilt.

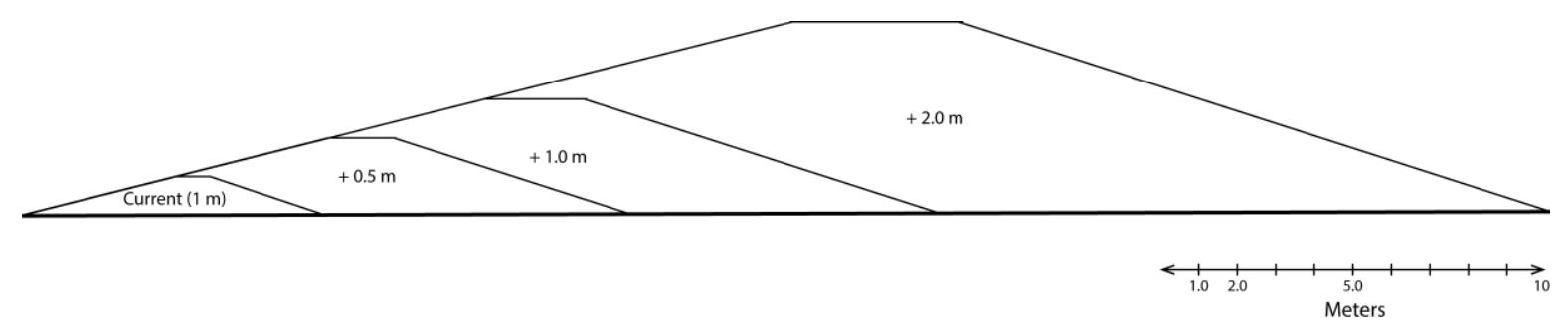

Figure 2. Cross-section of a levee depicted under different sea level rise scenarios. 
Table 3. Implications for levee design under different sea level rise scenarios.

\begin{tabular}{cccc}
\hline \multirow{2}{*}{$\begin{array}{c}\text { Sea Level Rise } \\
\text { Scenario }(\mathbf{m})\end{array}$} & Height $(\mathbf{m})$ & Wevee Dimensions & \\
\cline { 2 - 4 } & Width $(\mathbf{m})$ & Cross-Sectional Area $^{\mathbf{( m}} \mathbf{m}^{\mathbf{2}} \mathbf{)}$ \\
\hline 0 & Basis $=1$ & Basis $=7.9$ & Basis $=4.4$ \\
0.5 & 2 & 15.8 & 17.6 \\
1.0 & 3 & 23.7 & 39.6 \\
2.0 & 5 & 39.5 & 110.0 \\
5.0 & 11 & 86.9 & 532.4 \\
\hline
\end{tabular}
${ }_{1}^{1}$ Based on levee design with a seaward ratio of 1:4 and a landward ratio of 1:3. The relationship between sea level
rise and levee height assumes that wave breaking is depth limited.

We hypothesized that land costs are likely to be a major driver of the cost of higher levees, since more land must be acquired as the width of the levee increases to support its height (see Table 3) [33,35]. To calculate this cost, we obtained parcel-scale market cost estimates from an online real estate database (https:/ / www.zillow.com/) on two separate dates, and calculated the average land costs for all parcels in each county. Prior research in the field of urban economics has shown these estimates to be accurate [37,38]. We increased these base costs slightly to reflect costs associated with eminent domain purchases in the American legal context. We then multiplied these average costs by the number of parcels needed to accommodate higher levees for each sea level rise scenario. This parcel calculation was applied to both the simple and complex levee approaches resulting in Approaches \#2 and \#4.

In Table 4, we present the final numbers we used for these four different cost estimation approaches. We used the median value of the data we found in the literature for either landforms or walls to define our "typical" unit cost. We used the high and low cost number from the literature for our range. The cost of purchasing land to address the width of the levee varies based on county, shoreline, and sea level rise scenario. In Table 4 , we provide the range; however, the actual numbers can be accessed as described in Section 2.3.

Table 4. Cost estimates by infrastructure type and analysis approach.

\begin{tabular}{cccc}
\hline Cost Approach & $\begin{array}{c}\text { Static Landforms } \\
\text { Typical (Range) }\end{array}$ & $\begin{array}{c}\text { Static Walls Typical } \\
\text { (Range) }\end{array}$ & $\begin{array}{c}\text { Land Cost (Billions } \\
\text { of 2016 USD\$) }\end{array}$ \\
\hline $\begin{array}{c}\text { (1) Simple, without parcels } \\
\text { (2) Simple, with parcels }\end{array}$ & $\$ 8.0( \pm \$ 4.0)$ & $\$ 218.0( \pm \$ 75.0)$ & $\begin{array}{c}\text { NA } \\
1.4 \text { to 22.0 }\end{array}$ \\
\hline $\begin{array}{c}\text { (3) Complex, without parcels } \\
\text { (4) Complex, with parcels }\end{array}$ & $\begin{array}{c}\text { Raising }>3 \text { m: Times 3 } \\
\text { Raising }>1.5 \text { m: Times 2 } \\
\text { Raising }<1.5 \text { m: Times 1 }\end{array}$ & $\begin{array}{c}\text { Raising }>0.5 \text { m: Times } 4 \\
\text { Raising }<0.5 \text { m: Times 0.5 }\end{array}$ & $\begin{array}{c}\text { NA } \\
1.4 \text { to 22.0 }\end{array}$ \\
\hline
\end{tabular}

\subsection{Data and Methods Access}

We made our datasets and detailed methods available through UC Berkeley's online data archive, known as DASH. The first dataset contains the water exceedance calculations for the three different shorelines we describe, as well as the full shore zone dataset, and can be accessed at this URL: https://doi.org/10.6078/D1W30C. The second dataset contains the cost calculations for the three different shorelines we describe, as well as the full shore zone dataset, and can be accessed at this URL: https:/ / dx.doi.org/10.6078/D1KK59. Additionally at each URL the code and models we used can be downloaded. Finally, the three publicly available datasets used can be accessed from their original sources. 


\section{Results}

\subsection{Description of the Current Shore Zone and Alternative Future Shorelines}

Using Hill's classification system [26], we defined four broad types of coastal infrastructure: (1) static landforms; (2) dynamic landforms; (3) static walls; and (4) dynamic walls. We evaluated all 169,000 30-m shoreline segments within the shore zone, all as described in Table 2. Each shoreline segment was only classified as a single one of the four types, and our analyses of the shorezone (as an area within which structures are placed or already exist) capture dual protection scenarios. In this area, we found that the San Francisco (SF) Bay shore zone is predominantly comprised of static landforms (69\% of the entire SF Bay edge). The remainder contains 18\% dynamic landforms, $12 \%$ static walls, and less than $1 \%$ dynamic walls. These structures, which comprise the set of existing structures, are not necessarily connected to each other, and are often not certified as effective flood protection structures.

In order to define organized future "shorelines" from this set of existing structures and compare their estimated costs, we defined three alternative shoreline positions relative to today's MHHW. We used ecological boundaries to generate our Shorelines A, B, and C, as described in Section 2.2. If flood protection structures are built along the most bayward line, Shoreline $A$, the structures would eliminate saltwater wetlands. The most landward future shoreline in this study, Shoreline C, would allow the beneficial flooding of wetland habitats by saltwater to continue, while still protecting most of the developed land. The wetlands that remain exposed would likely require additional sediment to keep pace with sea level rise [15]. Shoreline B is defined by the boundary between saltwater wetland vegetation and freshwater wetland vegetation, and lies between Shorelines A and C.

The map in Figure 3 shows these three alternative future shorelines for the SF Bay, which we used as the basis for our cost comparisons. In places with limited wetland vegetation, such as the Central Bay, the three shorelines converge. However, in portions of the Bay with expansive wetland vegetation and more gradual slopes, such as San Pablo and Suisun Bay, the three shorelines are very different.

These alternative shoreline alignments are different both in length and in the percentage of the different shoreline types we have defined. As shown in Figure 4, the more landward shorelines are longer. Shoreline C, which is the most landward, is $2154 \mathrm{~km}$ long; Shoreline B, which is at the boundary of freshwater and saltwater wetlands, is $1340 \mathrm{~km}$ long; and Shoreline A, at approximately the MHHW line, is $967 \mathrm{~km}$ long. Figure 4 also shows the composition of each shoreline in terms of our four shoreline types. Shoreline A is unique because of a more even split between the two landform categories, static and dynamic. Dynamic walls are $0.1 \%$ of all three shorelines and thus do not appear in the figure. 


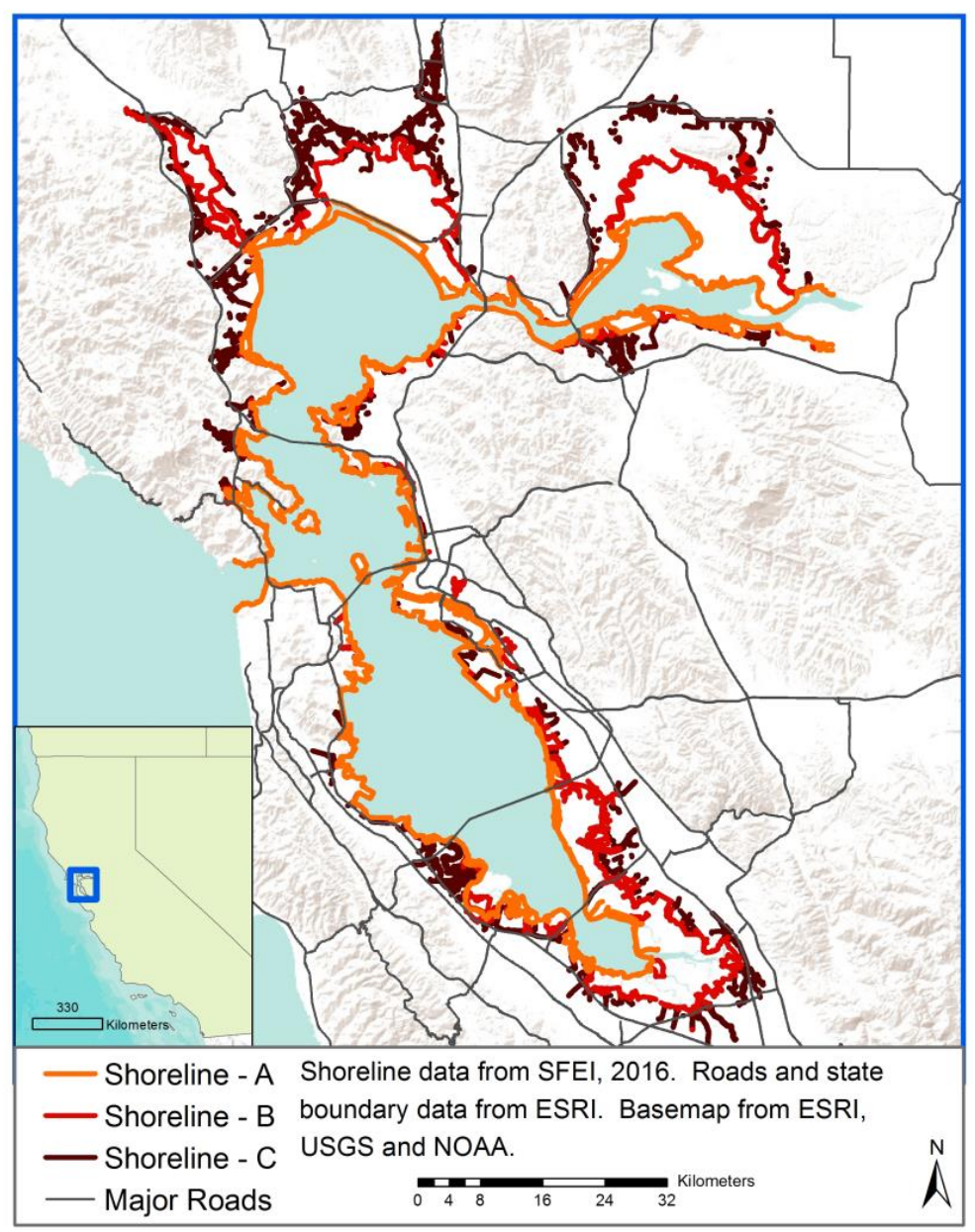

Figure 3. Map showing the full San Francisco Bay study area and the location of the three different shorelines-A, B, and C-we designated for comparative analysis purposes.

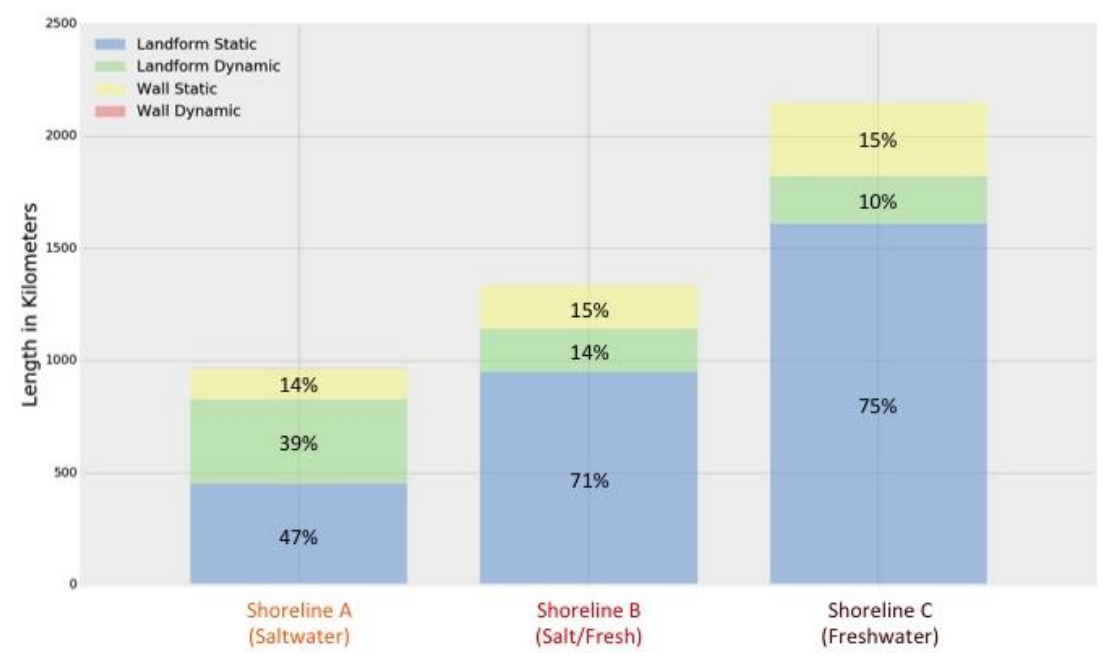

Figure 4. Chart showing each of the three shorelines A, B, and C. For each, the bar chart shows their total length, the length of each of the four coastal infrastructure types, and the percentage of each coastal infrastructure type. Note that dynamic walls are less than $1 \%$, and therefore cannot be seen clearly in this figure. 


\subsection{Rapid Assessment of Water Exceedance Levels}

Here, we used the CoSMoS projections of future water levels [30] to evaluate the potential costs of raising current coastal protective infrastructure to meet future sea level rise scenarios. We calculated the water height exceedance level by calculating the difference in height between the projected water levels and the structure for all four types of shoreline structures in our defined shore zone. Figure 5 shows the summary median values for four different sea level rise scenarios, without including storm surges. Note that in Figures 5 and 6, we present the "no-storm-surge" condition. We do this to separate the impacts of a permanently higher mean sea level from the impacts of temporary storm events, in which floodwaters recede when the event is over. Both types of flooding are important, but the adaptation cost and response to each might be different. All four types of shoreline structures see an increase in exceedance as sea levels rise; however, dynamic landforms (typically wetlands) face the greatest amount of water level exceedance as sea levels rise.

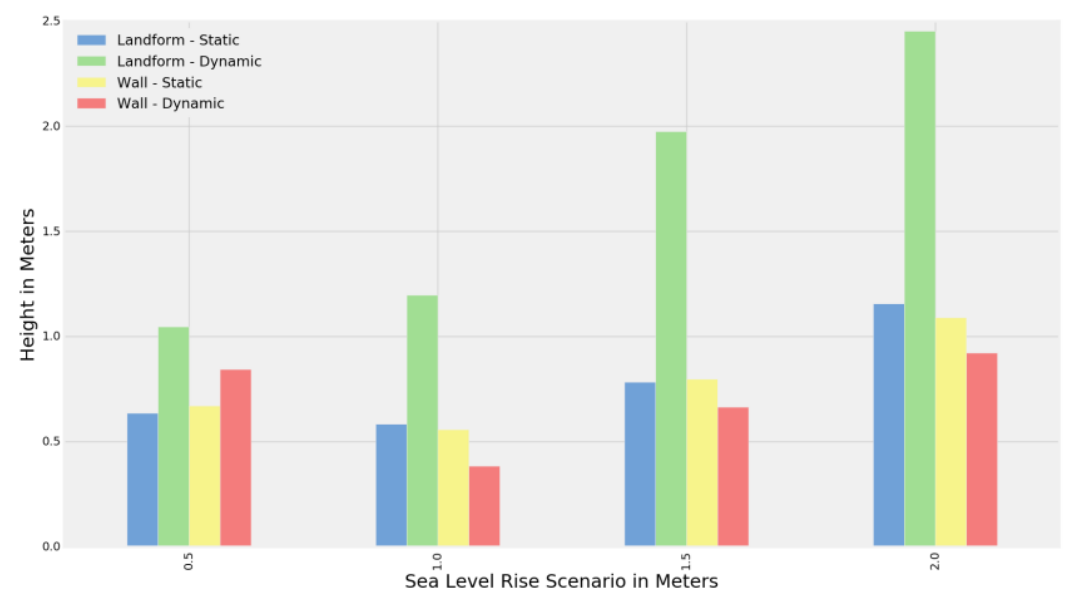

Figure 5. Figure showing the median height of the water that would exceed the top of the four types of protective infrastructure - static landforms, dynamic landforms, static walls, or dynamic walls—with sea level rise scenarios between 0.5 and $2 \mathrm{~m}$.

Next, we calculated exceedance heights for each of the three specific shorelines we designated for cost comparison purposes: Shorelines A, B and C. Figure 6 shows the exceedance heights for the no-storm-surge condition under four different sea level rise scenarios. Here, we see an overall trend of an increase in exceedance as sea levels rise for all three shorelines.

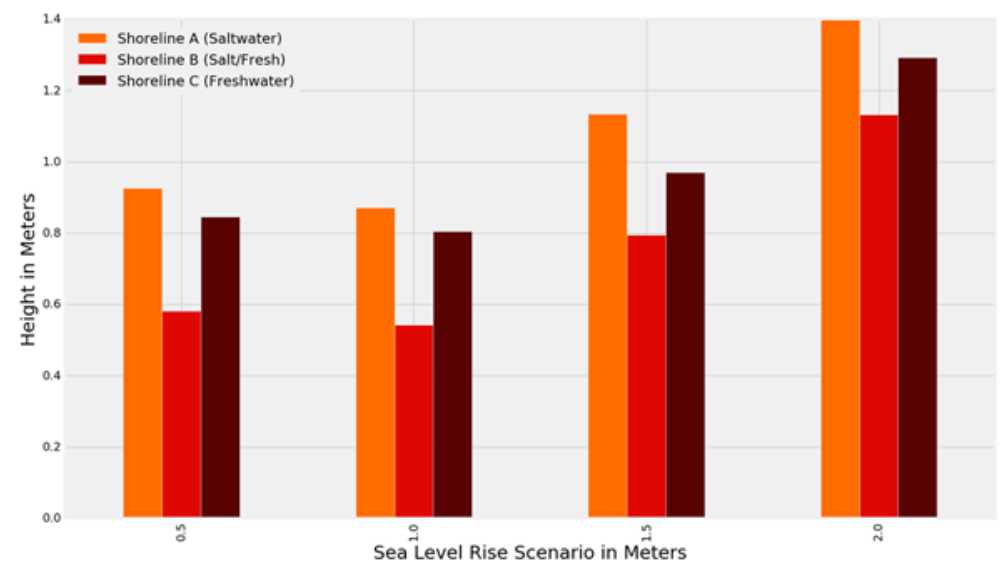

Figure 6. Figure showing the median height of the water that would exceed the height of thousands of line segments that represent the top of the three shorelines-A, B, and C-with sea level rise scenarios between 0.5 and $2 \mathrm{~m}$. 


\subsection{Comparing Cost Estimation Approaches}

Here, we present our cost estimation results based on the different cost estimation approaches described in Section 2.2 and summarized in Table 4.

Figure 7 shows our results from applying all four cost estimation approaches to Shoreline B, which sits on the boundary of saltwater vegetation and freshwater vegetation. This figure shows the total regional cost for the no-storm-surge condition under four different sea level rise scenarios. All four of the cost estimation approaches we used indicate that the costs of raising walls dominate the total cost estimate, constituting between 70 and 90 percent of the overall cost.

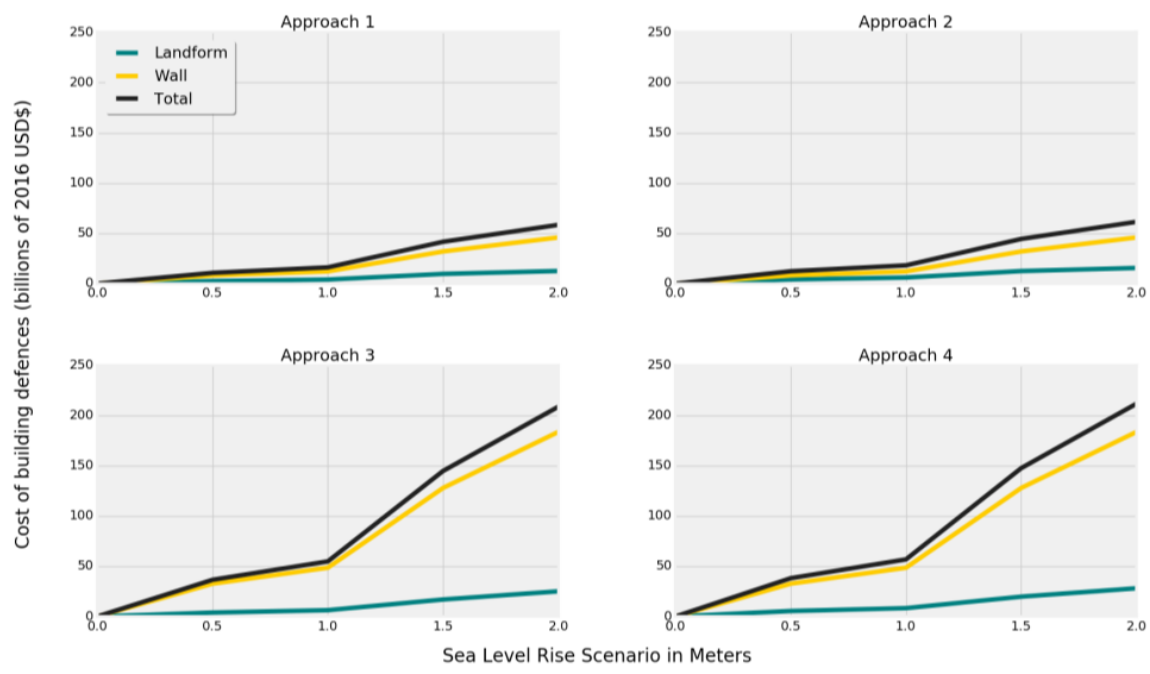

Figure 7. Figure comparing the four different cost calculation approaches for Shoreline B in billions of 2016 USD\$. The two approaches on the left side (\#1 and \#3) do not include land purchase costs for the landform cost calculation, whereas the two approaches on the right side (\#2 and \#4) include a land purchase cost. The upper two approaches (\#1 and \#2) use a linear calculation for landforms and wall cost calculation, whereas the two approaches on the bottom (\#3 and \#4) have a more nuanced approach to levee and wall cost calculations. Each subplot shows landform, wall, and total costs in billions of dollars starting at no sea level rise and extending to $2.0 \mathrm{~m}$ of sea level rise.

Cost increases are relatively moderate below $1 \mathrm{~m}$ of relative sea level rise, but increase much more rapidly beyond that. We found the average cost increase among all four approaches to be $\$ 37$ billion 2016 USD\$ in order to raise existing structures to prevent overtopping from $0 \mathrm{~m}$ of sea level rise to $1 \mathrm{~m}$ of sea level rise. In contrast, we found the average increase to be $\$ 99$ billion 2016 USD\$ for the total costs of raising the structures to prevent overtopping caused between $1 \mathrm{~m}$ and $2 \mathrm{~m}$ of sea level rise. The cost of adapting to the first meter of sea level rise is predicted to be $\$ 62$ billion 2016 USD\$ lower than the cost of adapting to the second meter of sea level rise. In addition, Figure 7 shows that using a cost estimate that reflects changes in levee volume, and that uses wall replacement thresholds appropriate for a seismic region, has a large impact on the total cost (Approaches \#3 and \#4), whereas adding the cost of purchasing land (Approaches \#2 and \#4) produces a smaller impact on total costs.

Figure 8 shows the impact of land purchase costs alone (i.e., excluding wall costs) on all three shorelines by comparing our cost estimates from Approaches \#1 and \#2. Adding the estimated cost of purchasing private land increases the cost of adaptation. However, the impact of the land purchases is much greater for Shoreline C, which is the most landward of the shorelines. For Shorelines A and B, the difference between including estimated land costs and not including land costs is \$1.3 billion 2016 USD\$ at the lowest, and \$3.02 billion 2016 USD\$ at the highest. For Shoreline C, the longest and most landward shoreline, including land costs produces a difference between $\$ 7.8$ and \$11.2 billion 2016 USD\$. The reason for this difference is that Shoreline C contains significantly more private parcels that would need to be purchased, compared with Shorelines A and B. 


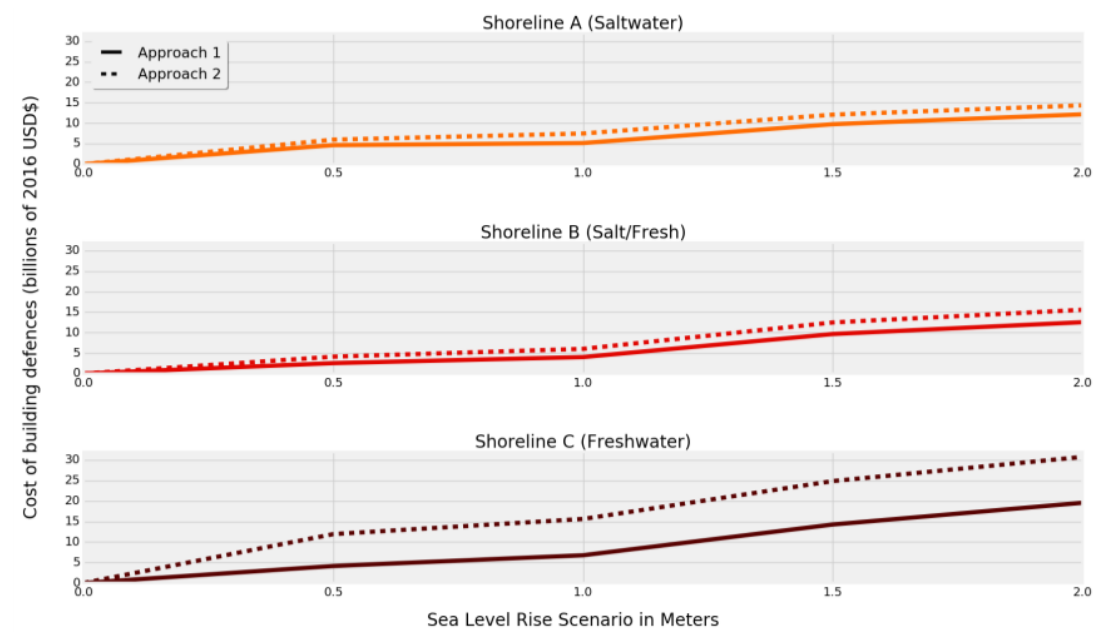

Figure 8. Figure comparing the impact of the land purchase costs across the three different shorelines-A, B, and C-in billions of 2016 USD\$. Approach 1 (shown as a solid line) does not include land purchase costs, whereas Approach 2 (shown as a dashed line) includes a land purchase cost. Each subplot shows only the landform costs in billions of dollars.

Finally, we wanted to test the sensitivity of our cost estimation approach to traditional structural requirements for freeboard, defined as the distance between the normal water line and the top of a flood protection structure. While there are important functional reasons for these requirements, different types of infrastructure (wetlands vs. levees, for example) may use different engineering standards [39]. The design of resilient urban districts that tolerate some flooding can also reduce freeboard requirements for some types of shoreline structures.

Figure 9 shows the sensitivity of our cost estimation method to additional freeboard by displaying five different freeboard scenarios. For Shoreline B, we initially examined four different sea level rise scenarios with no storm surge and no freeboard. Then, we calculated the cost impact of requiring up to $1 \mathrm{~m}$ of freeboard, in increments of $0.25 \mathrm{~m}$. This calculation uses Approach \#3, which includes volume-based and seismically influenced cost calculations, but does not include land purchase costs. Figure 9 shows that requiring more freeboard has a large impact on overall costs. In our final modeling of estimated costs, presented in the next section, we used a freeboard of $0.61 \mathrm{~m}$ ( 2 feet) to represent current Federal Emergency Management Agency (FEMA) requirements [32].

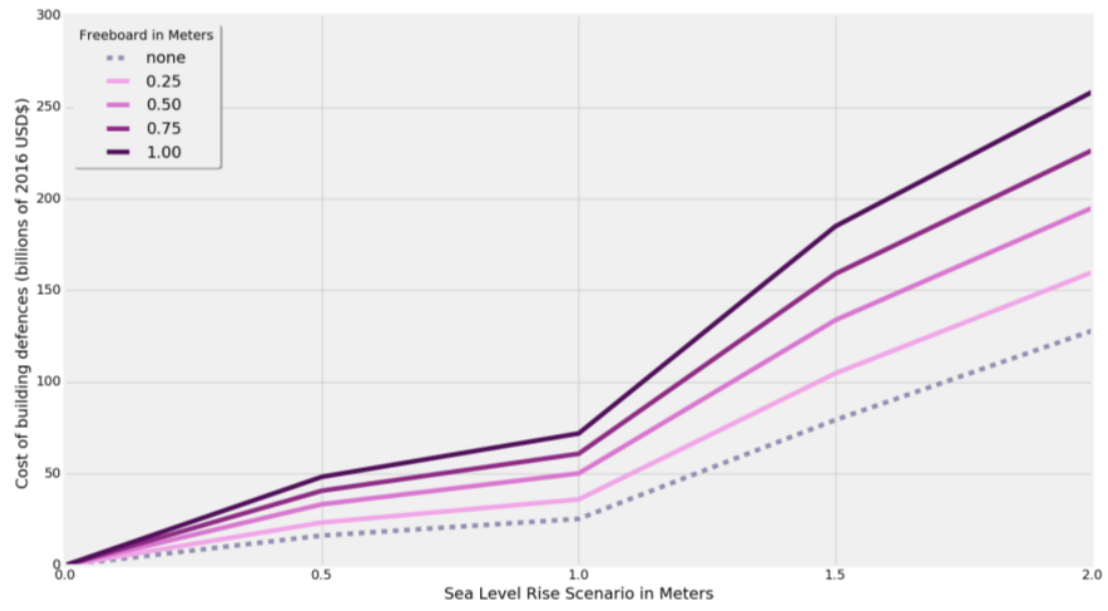

Figure 9. Figure showing the impact of different freeboard heights on the total cost for Shoreline B in billions of 2016 USD\$. This calculation is based on Approach \#3. 


\subsection{Overall Cost Estimates}

In this section, we present our final cost estimates for the full Bay-wide scale of physical shoreline adaptation within the constraints of our assumptions. All of the results here reflect the application of our methods using Approach \#4 (complex with land costs), with the freeboard requirement set at $0.61 \mathrm{~m}$ as noted above.

Table 5 and Figure 10 show a comparison of the three different shorelines we designated: A, B, and $\mathrm{C}$. For each shoreline, we show a typical cost, which is based on an intermediate value from the data summarized in Table 1. The range is based on the distribution and the high and low end of the data summarized in Table 1. This comparison shows that Shorelines A and B are similar to each other, while Shoreline C stands out as significantly more expensive to protect.

Table 5. Estimated costs for raising coastal protective infrastructure to meet future sea level rise scenarios for the three designated potential shorelines in billions of USD\$.

\begin{tabular}{|c|c|c|c|c|c|c|c|c|c|}
\hline \multirow{2}{*}{$\begin{array}{c}\text { Sea } \\
\text { Level } \\
\text { Rise } \\
\text { Scenario }\end{array}$} & \multicolumn{3}{|c|}{$\begin{array}{c}\text { Shoreline A } \\
\text { (Saltwater) }\end{array}$} & \multicolumn{3}{|c|}{$\begin{array}{l}\text { Shoreline B } \\
\text { (Salt/Fresh) }\end{array}$} & \multicolumn{3}{|c|}{$\begin{array}{l}\text { Shoreline C } \\
\text { (Freshwater) }\end{array}$} \\
\hline & $\begin{array}{l}\text { Range } \\
\text { Low }\end{array}$ & Typical & $\begin{array}{l}\text { Range } \\
\text { High }\end{array}$ & $\begin{array}{l}\text { Range } \\
\text { Low }\end{array}$ & Typical & $\begin{array}{l}\text { Range } \\
\text { High }\end{array}$ & $\begin{array}{c}\text { Range } \\
\text { Low }\end{array}$ & Typical & $\begin{array}{c}\text { Range } \\
\text { High }\end{array}$ \\
\hline $0.5 \mathrm{~m}$ & $\$ 24$ & $\$ 39$ & $\$ 53$ & $\$ 25$ & $\$ 38$ & $\$ 51$ & $\$ 43$ & $\$ 63$ & $\$ 83$ \\
\hline $1.0 \mathrm{~m}$ & $\$ 33$ & $\$ 51$ & $\$ 70$ & $\$ 37$ & $\$ 57$ & $\$ 77$ & $\$ 69$ & $\$ 103$ & $\$ 137$ \\
\hline $1.5 \mathrm{~m}$ & $\$ 81$ & $\$ 126$ & $\$ 172$ & $\$ 95$ & $\$ 148$ & $\$ 200$ & $\$ 157$ & $\$ 240$ & $\$ 323$ \\
\hline $2.0 \mathrm{~m}$ & $\$ 116$ & $\$ 182$ & $\$ 248$ & $\$ 136$ & $\$ 212$ & $\$ 287$ & $\$ 217$ & $\$ 335$ & $\$ 453$ \\
\hline
\end{tabular}

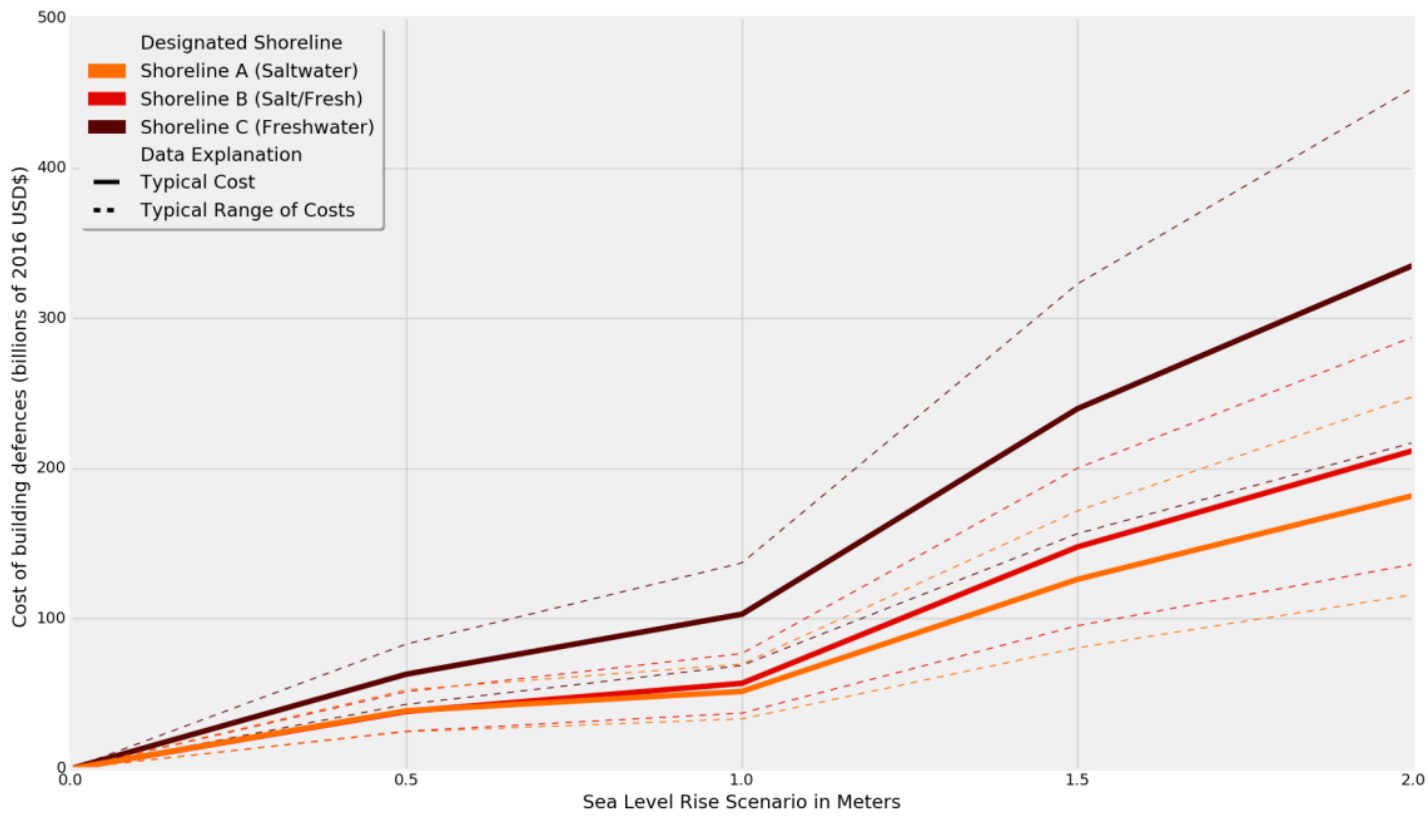

Figure 10. Figure comparing the average and the range of potential costs to raise the protective infrastructure along each of the three different shorelines. Costs are based on current infrastructure type-landform or wall-being raised to meet future water levels in a no-storm-surge condition and sea level rise scenarios. The cost estimates are done using Approach \#4 and are shown as billions of 2016 USD\$.

We also compared the Bay-wide costs of raising coastal infrastructure high enough to prevent flooding from new sea levels combined with a storm surge scenario (the 100-year or $1 \%$ storm surge). We display the "storm-vs.-no storm" comparison for our cost estimate for Shoreline B in Figure 11. In a 1-m sea level rise scenario, the cost goes from an average of $\$ 56.8$ billion 2016 USD $\$$ in a no-storm-surge condition to $\$ 98.9$ billion 2016 USD $\$$ in a one-percent chance storm condition. It is 
significant to note that raising infrastructure to prevent flooding from temporary storm events along with sea level rise is almost twice as expensive as raising the same structures to prevent flooding from permanent sea level rise only, while adapting to temporary flooding on the landward side.

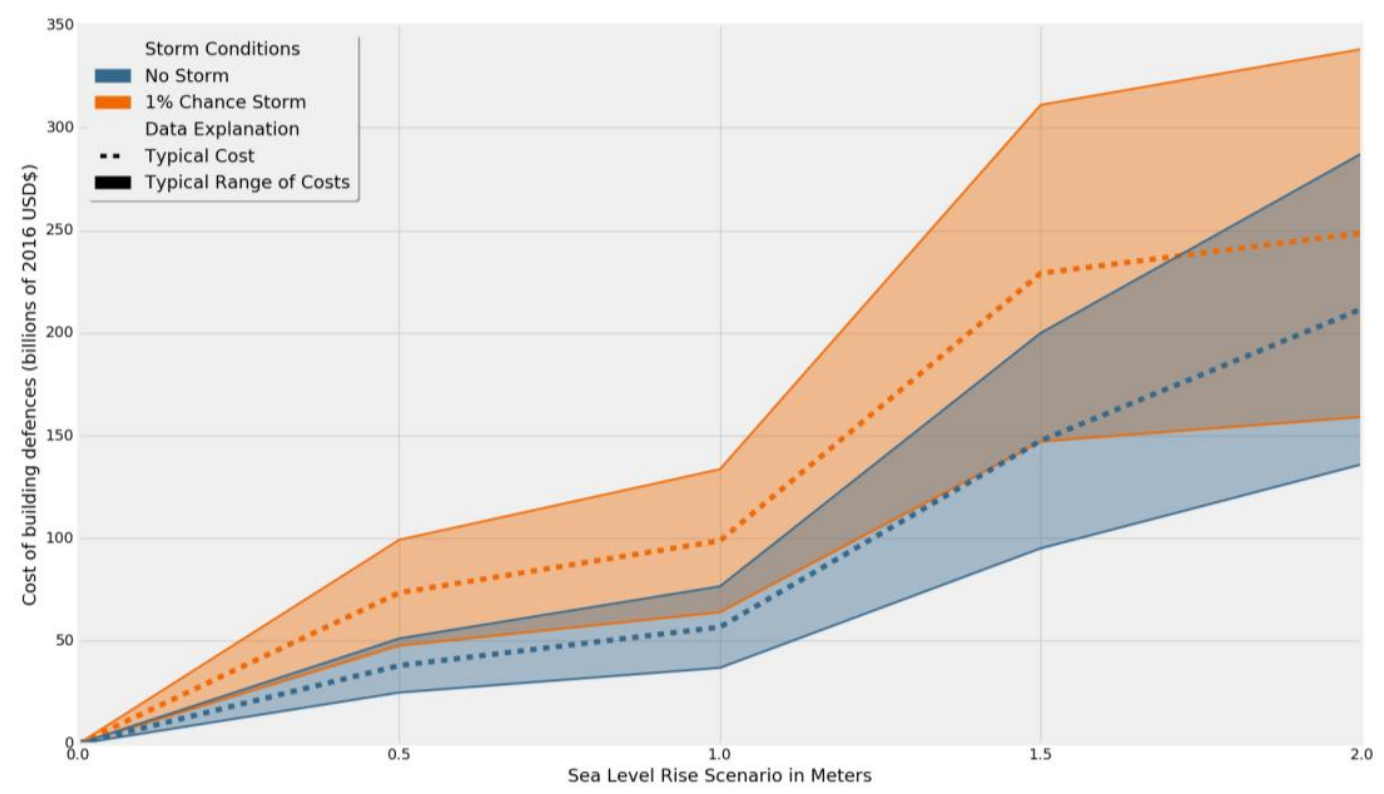

Figure 11. Figure showing the average and the range of potential costs under two different design scenarios for Shoreline B. The lines in blue show a scenario that assumes protective infrastructure would be designed to address only future sea level rise and not storm events. The lines in orange assume that protective infrastructure would be designed to address the $1 \%$ chance storm event as well as sea level rise. Costs are based on current infrastructure type-landform or wall-being raised to meet future water levels for sea level rise scenarios between $0 \mathrm{~m}$ and $2 \mathrm{~m}$. The cost estimates are done using Approach 3: complex cost approximations without parcel values and are shown as billions of 2016 USD\$.

\section{Discussion: Strategic Implications of Results}

\subsection{Implications for Alternative Shorelines and Design Strategies}

Coastal planning and engineering practitioners often suggest that the vulnerability of a shoreline can be reduced by shortening the overall length of the shoreline $[40,41]$. Our results show a lower cost for the shortest shoreline in Figure 10. However, our research raises specific concerns about this strategy. While we do find that the longest line (Shoreline $\mathrm{C}$ ) represents significantly more cost to adapt to future sea level rise, the other two shorelines (A and B) are likely to be similar to each other in cost despite their different lengths. If we weigh these costs against the value of ecosystem services provided by the intertidal zone, the middle shoreline (Shoreline B) appears to be optimal. In San Francisco Bay today, site managers and public agency planners are proposing projects to raise coastal structures along this middle shoreline (our Shoreline B) [25,32].

Prior research suggests that raising wall infrastructure types will be an order of magnitude more expensive than raising the landform infrastructure types. Our results, as shown in Figure 7, support this conclusion. Figure 7 shows that the cost of raising the height of existing walls, which currently make up only $15 \%$ of Shorelines B and C, has a significantly greater impact on total cost than the cost of raising landforms. If we re-calculate our estimated cost for Shoreline B using only walls, the total cost increases by 7.5 to 8.9 times the cost of a combined landform-and-wall coastal shoreline. From a cost perspective, landform-based shoreline infrastructure may be a better investment over time. Switching to wall-based adaptation where there are no walls today introduces the risk of locking future generations into a much more expensive strategy. 
There is significant debate both in the literature and in practice as to the ideal height of protective shoreline infrastructure, and the associated amount of temporary flooding that urban development would need to accommodate. On the one hand, reduction in risk is critical and protective infrastructure should be designed to prevent disastrous flooding events. On the other hand, researchers using models find that exposure to some flooding can reduce overall vulnerability [42], and may even promote the development of more resilient urban districts (sometimes called "floodable development"). Planners in the SF Bay region are currently trying to determine an appropriate height for raised structures in locations where the cost of providing coastal protection is outweighed by the multiple benefits that the protection provides [32,36]. Figure 11 shows that designing infrastructure to protect against infrequent, extreme flood events would be significantly more expensive than protecting against the permanent landward movement of the mean water line. While protecting against the 10 or 20 year storm may make financial sense, designing urban districts that are adapted to temporary flooding may be a better way to share costs and risks. Our results present important strategic implications for the design of vulnerability studies, and for setting goals in adaptation plans. If planners seek to accept some flooding while protecting against permanent inundation, physical plans might include floodable urban districts [43]. Adaptation costs could then be shared and optimized in new ways.

Actual adaptation strategies are likely to be complex in their spatial patterns and mix of structures. Previous land use is likely to influence realignment [8]. Rivers will contribute additional flooding problems, exacerbated by the increased incidence of extreme precipitation [7]. Coastal structures will also have upstream impacts. In other regions, even movable barriers, such as tide gates, have been shown to produce negative impacts on upstream wetlands and fish populations [44-47]. These, and a host of other specific considerations, would need to be taken into account when selecting a site-specific adaptation strategy. Further research is required to address all of these unique challenges. However, we hope that our work can highlight the cost-specific limitations of a regional strategy that relies on walls and static landforms, such as levees and terraces.

\subsection{Benefits and Limitations of Our Cost Estimation Method}

The ability to easily calculate the costs of protective infrastructure needed to address sea level rise would be a powerful tool for state and regional agencies, coastal planners, and local officials. The rapid assessment approach we present in this study is especially useful where relatively accurate regional datasets are available. Additionally, our method allows planners to customize key policy components, such as the desired freeboard height, to conduct sensitivity analyses. This may also allow our approach to be used in other geographic regions with different wave energy regimes, and therefore different structural design requirements. Our approach currently does not account for other major project costs, such as conducting required planning studies, managing soil contamination, and maintaining project contingency reserves. In addition, we have not included the capital, operations, and maintenance costs of pumps that will be required to remove stormwater when levees or other structures block the flow of runoff and tributaries, and to lower future groundwater levels. These very significant costs can also be estimated, but would require hydrologic flow data and groundwater modeling along shoreline segments to approximate the volumes of pumping that will be required.

\subsection{Potential Future Research}

Three important questions for future research arose during this project. One is whether and how coastal protective infrastructure can be paired with adjacent land uses and ecosystems to provide the greatest combined level of resilience [26]. Specifically, areas with high groundwater and riverine settings will require significant analysis to ensure that precipitation-based flooding and storm surge are both accounted for in designs and plans. Studies of possible pairings would allow planners to evaluate specific sites and develop a strategy for districts within regions.

Second, our results provide only the first step in the kind of full cost benefit analysis that is required for proper adaptation planning. The costs associated with potential damages as well as the 
significant impacts to physical assets and human populations will be a key factor in determining the levels of protection required. Moreover, estuary regions must consider how adaptation will affect ecosystem services, and seek to achieve greater connectivity for species and habitat. Without this advance planning, key functions can be completely lost as new or raised shoreline structures block hydrologic flows, wetland migration, and the movement of animals. Our research represents only a first step in estimating the costs of protective infrastructure using different spatial shoreline positions. It is essential to compare these costs to the value of assets that would be protected, including the value of key ecosystem services.

Finally, this study raised the question of whether it will be possible to identify thresholds associated with sea level rise and other drivers of coastal flooding. What thresholds in rates or magnitudes of processes would create unsafe conditions for occupying coastal developments? What thresholds might push coastal adaptation onto different adaptation pathways, for example, away from protection and towards realignment? Our method provides a starting point for exploring these questions from a cost perspective. The method would be enhanced by incorporating both additional capital and planning costs, as well as secondary costs such as those associated with the operation and maintenance of pumps. Including operations and maintenance costs would enrich the current method and provide for an evaluation that could identify different preferences among the alternative strategies.

\section{Conclusions}

\subsection{Strategic Physical Design Implications}

Given our assumptions about replacement thresholds, walls are significantly more expensive than levees and should only be used as a last resort approach to protection. Building them may create liabilities rather than assets for future generations, who will bear the costs of removing or replacing them. In general, creating structures that can fail catastrophically is unlikely to contribute to resilience over multiple decades when the rate of environmental change is accelerating, creating a greater likelihood of failure. Moreover, walls are typically single-purpose structures that do not provide benefits of recreation, carbon sequestration, and other ecosystem services. Walls, even movable barriers such as tide gates, produce negative impacts on upstream wetlands and fish populations [44-47].

When it comes to identifying an appropriate shoreline, our work suggests that defending the shortest shoreline may not be the best adaptation solution. Based on our approximation of the relative costs, Shoreline B (at the boundary between saltwater habitat and freshwater habitat) may be preferable to the shortest possible shoreline in this study (Shoreline A). Shoreline B has similar costs, but produces multiple benefits from ecosystem services. Shoreline $C$, which was the most expensive overall, also raises issues of unique flooding problems that occur where freshwater or brackish tributaries meet a saltwater body. Freshwater flooding driven by rainfall can combine with rising groundwater and saltwater flooding to create extreme flood conditions. These points of intersection among flows may require the realignment of shorelines, with the relocation of urban districts and infrastructure. Or, they could be locations where new strategies for human occupation of the shore zone are tested, between Shoreline B and Shoreline C. Floating concrete roadways, stormwater ponds, floating urban blocks, and freshwater habitat could form a mosaic of new development strategies that protect existing sewage treatment plants, which are often located at the intersections of fresh and salt water. This is a geographic zone that needs extensive further study in order to avoid the expansion or introduction of maladaptive strategies.

\subsection{Strategic Regulatory Implications}

We suggest that shoreline adaptation would be more successful if the shoreline structures continue to allow flooding in extreme events. While there is significant debate both in the literature and in practice as to the ideal design height for shoreline protective infrastructure, our results show 
clearly that creating requirements to design coastal structures with certain freeboard heights or storm surge expectations has a large impact on costs. Freeboard heights and other storm-specific design requirements should be set to reflect the intended purpose of the shoreline infrastructure, and its specific context within the shore zone. If coastal structures are designed to allow some overtopping without structural failure, higher sea levels can be allowed to produce temporary flooding from storm events. Periodic, temporary flooding can drive urban development to become more resilient by being re-designed to accommodate some floodwaters [42,43].

\subsection{Strategic Economic and Overall Approach Implications}

Most importantly, this paper illustrates the clear benefits of using a simplified typology to categorize shoreline types and calculate initial cost estimates. Working with a combination of Python and GIS enables our approach to handle very large datasets that are crucial for a large regional area. Moreover, our unit cost approach allows us to explore and compare different components of adaptation costs. Specifically, we find that the land purchase costs for levees contribute less to the overall regional cost than expected. Additionally, we see that triggers for replacing walls are a key driver of the total regional costs. We think this approach shows great promise for helping regional planners address critical strategic climate adaptation questions.

Acknowledgments: This study was performed as part of Daniella Hirschfeld's Ph.D. thesis work. Funding was provided by the McQuown Fellowship. SFEI and Point Blue provided data and assistance with data interpretation that was incredibly helpful to our work. Ellen Plane assisted by editing map data and constructing the shoreline alternatives, and helped to compile case studies of costs. Their support was greatly appreciated.

Author Contributions: D.H. and K.E.H. conceived and designed the key research questions and general methods collaboratively; D.H. performed the data collection and detailed model design; D.H. and K.E.H. analyzed the data; D.H. developed the figures and wrote Sections 1-4; K.E.H wrote Section 5 and contributed significant editing to the full paper.

Conflicts of Interest: The authors declare no conflict of interest.

\section{References}

1. Aerts, J.; Botzen, W.; Bowman, M.; Dircke, P.; Ward, D.I. Climate Adaptation and Flood Risk in Coastal Cities; Routledge: Abingdon, UK, 2013; ISBN 978-1-136-52893-4.

2. Brody, S.D.; Zahran, S.; Maghelal, P.; Grover, H.; Highfield, W.E. The Rising Costs of Floods: Examining the Impact of Planning and Development Decisions on Property Damage in Florida. J. Am. Plan. Assoc. 2007, 73, 330-345. [CrossRef]

3. Hill, K. Climate-Resilient Urban Waterfronts. In Climate Adaptation and Flood Risk in Coastal Cities; Routledge: Abingdon, UK, 2013; ISBN 978-1-136-52893-4.

4. Nicholls, R.J.; Wong, P.P.; Burkett, V.R.; Codignotto, J.O.; Hay, J.E.; McLean, R.F.; Ragoonaden, S.; Woodroffe, C.D. Coastal Systems and Low-Lying Areas. In Climate Change 2007: Impacts, Adaptation and Vulnerability. Contribution of Working Group II to the Fourth Assessment Report of the Intergovenmental Panel on Climate Change; Perry, M.L., Canziani, O.F., Palutikof, J.P., van der Linden, P.J., Hanson, C.E., Eds.; Cambridge University Press: Cambridge, UK, 2007; pp. 315-356.

5. IPCC. Summary for Policymakers. In Climate Change 2013: The Physical Science Basis. Contribution of Working Group I to the Fifth Assessment Report of the Intergovernmental Panel on Climate Change; Stocker, T.F., Qin, D., Plattner, G.-K., Tignor, M., Allen, S.K., Boschung, J., Nauels, A., Xia, Y., Bex, V., Midgley, P.M., Eds.; Cambridge University Press: Cambridge, UK; New York, NY, USA, 2013.

6. Rosenzweig, C.; Solecki, W.D.; Blake, R.; Bowman, M.; Faris, C.; Gornitz, V.; Horton, R.; Jacob, K.; LeBlanc, A.; Leichenko, R.; et al. Developing coastal adaptation to climate change in the New York City infrastructure-shed: Process, approach, tools, and strategies. Clim. Chang. 2011, 106, 93-127. [CrossRef]

7. Wahl, T.; Jain, S.; Bender, J.; Meyers, S.D.; Luther, M.E. Increasing risk of compound flooding from storm surge and rainfall for major US cities. Nat. Clim. Chang. 2015, 5, 1093-1097. [CrossRef]

8. French, P.W. Managed realignment? The developing story of a comparatively new approach to soft engineering. Estuar. Coast. Shelf Sci. 2006, 67, 409-423. [CrossRef] 
9. Reeder, T.; Ranger, N. How Do You Adapt in an Uncertain World? Lessons from the Thames Estuary 2100 Project. Available online: http:/ / www.worldresourcesreport.org/ (accessed on 15 April 2015).

10. Doody, J.P. Coastal squeeze and managed realignment in southeast England, does it tell us anything about the future? Ocean Coast. Manag. 2013, 79, 34-41. [CrossRef]

11. Nicholls, R.J.; Klein, R.J.T. Climate change and coastal management on Europe's coast. In Managing European Coasts; Vermaat, J., Salomons, W., Bouwer, L., Turner, K., Eds.; Environmental Science; Springer: Berlin/Heidelberg, Germany, 2005; pp. 199-226, ISBN 978-3-540-23454-8.

12. Ezer, T.; Corlett, W.B. Is sea level rise accelerating in the Chesapeake Bay? A demonstration of a novel new approach for analyzing sea level data. Geophys. Res. Lett. 2012, 39. [CrossRef]

13. Knowles, N. Potential Inundation Due to Rising Sea Levels in the San Francisco Bay Region; California Climate Change Center: Sacramento, CA, USA, 2009.

14. Heberger, M.; Cooley, H.; Moore, E.; Herrera, P.; Pacific Institute. The Impacts of Sea Level Rise on the San Francisco Bay; California Energy Commission: Sacramento, CA, USA, 2012.

15. Stralberg, D.; Brennan, M.; Callaway, J.C.; Wood, J.K.; Schile, L.M.; Jongsomjit, D.; Kelly, M.; Parker, V.T.; Crooks, S. Evaluating Tidal Marsh Sustainability in the Face of Sea-Level Rise: A Hybrid Modeling Approach Applied to San Francisco Bay. PLoS ONE 2011, 6, e27388. [CrossRef] [PubMed]

16. California Ocean Protection Council. Updating the State of California Sea-Level Rise Guidance Document. Available online: http:/ / www.opc.ca.gov/climate-change/updating-californias-sea-level-rise-guidance/ (accessed on 18 April 2017).

17. Griggs, G.; Arvai, J.; Cayan, D.; DeConto, R.; Fox, J.; Fricker, H.A.; Kopp, R.E.; Tebaldi, C.; Whiteman, L.; California Ocean Protection Council Science Advisory Team Working Group. Rising Seas in California: An Update on Sea Level Rise Science; California Ocean Science Trust: Oakland, CA, USA, 2017.

18. Kopp, R.E.; Horton, R.M.; Little, C.M.; Mitrovica, J.X.; Oppenheimer, M.; Rasmussen, D.J.; Strauss, B.H.; Tebaldi, C. Probabilistic 21st and 22nd century sea-level projections at a global network of tide-gauge sites. Earths Future 2014, 2, 2014EF000239. [CrossRef]

19. Brown, S.; Nicholls, R.J.; Hanson, S.; Brundrit, G.; Dearing, J.A.; Dickson, M.E.; Gallop, S.L.; Gao, S.; Haigh, I.D.; Hinkel, J.; et al. Shifting perspectives on coastal impacts and adaptation. Nat. Clim. Chang. 2014, 4, 752-755. [CrossRef]

20. Hill, K. Climate Change: Implications for the Assumptions, Goals and Methods of Urban Environmental Planning. Urban Plan. 2016, 1, 103. [CrossRef]

21. Bierbaum, R.; Smith, J.B.; Lee, A.; Blair, M.; Carter, L.; Iii, F.S.C.; Fleming, P.; Ruffo, S.; Stults, M.; McNeeley, S.; et al. A comprehensive review of climate adaptation in the United States: more than before, but less than needed. Mitig. Adapt. Strateg. Glob. Chang. 2013, 18, 361-406. [CrossRef]

22. Haasnoot, M.; Kwakkel, J.H.; Walker, W.E.; ter Maat, J. Dynamic adaptive policy pathways: A method for crafting robust decisions for a deeply uncertain world. Glob. Environ. Chang. 2013, 23, 485-498. [CrossRef]

23. Nordgren, J.; Stults, M.; Meerow, S. Supporting local climate change adaptation: Where we are and where we need to go. Environ. Sci. Policy 2016, 66, 344-352. [CrossRef]

24. Hirschfeld, D.; Hill, K.; Plane, E. SanFrancisco Bay-Adapt2SeaLevelRise-Case Studies; UC Berkeley Library DASH: Berkeley, CA, USA, 2017.

25. San Francisquito Creek Joint Powers Authority. SAFER Bay Project-Strategy to Advance Flood Protection, Ecosystems and Recreation along San Francisco Bay; San Francisquito Creek Joint Powers Authority: East Palo Alto/Menlo Park, CA, USA, 2016; p. 91.

26. Hill, K. Coastal infrastructure: A typology for the next century of adaptation to sea-level rise. Front. Ecol. Environ. 2015, 13, 468-476. [CrossRef]

27. San Francisco Estuary Institute (SFEI). San Francisco Bay Shore Inventory: Mapping for Sea Level Rise Planning GIS Data; San Francisco Estuary Institute: Richmond, CA, USA, 2016; Available online: http: / www.sfei. org/data/sf-bay-shore-inventory-gis-data\#sthash.ctGdURWD.dpbs (accessed on 2 February 2015).

28. San Francisco Estuary Institute (SFEI). Bay Area Aquatic Resource Inventory (BAARI); San Francisco Estuary Institute: Richmond, CA, USA, 2009. Available online: http://www.sfei.org/baari\#sthash.MKGpl13z.dpbs (accessed on 13 May 2015).

29. United States Geological Survey (USGS). Coastal Storm Modeling System (CoSMoS) Version 2.1: San Francisco Bay Area. Flood Extent and Depth; Point Blue Conservation Science: Petaluma, CA, USA, 2014. Available online: www.ourcoastourfuture.org (accessed on 31 August 2017). 
30. Barnard, P.L.; van Ormondt, M.; Erikson, L.H.; Eshleman, J.; Hapke, C.; Ruggiero, P.; Adams, P.N.; Foxgrover, A.C. Development of the Coastal Storm Modeling System (CoSMoS) for predicting the impact of storms on high-energy, active-margin coasts. Nat. Hazards 2014, 74, 1095-1125. [CrossRef]

31. ChrisMuir. Zillow Scraper for Python Using Selenium. 2017. Available online: https://github.com/ ChrisMuir/Zillow / (accessed on 30 March 2017).

32. United States Army Corps of Engineers. South San Francisco Bay Shoreline Phase I Study - Final Integrated Document; United States Army Corps of Engineers: San Francisco, CA, USA, 2015.

33. Jonkman, S.N.; Hillen, M.M.; Nicholls, R.J.; Kanning, W.; van Ledden, M. Costs of Adapting Coastal Defences to Sea-Level Rise-New Estimates and Their Implications. J. Coast. Res. 2013, 29, 1212-1226. [CrossRef]

34. Lowe, J.; Battalio, B.; Brennan, M. Analysis of the Costs and Benefits of Using Tidal Marsh Restoration as a Sea Level Rise Adaptation Strategy in San Francisco Bay; The Bay Institute: San Francisco, CA, USA, 2013.

35. Linham, M.M.; Nicholls, R.J. Technologies for Climate Change Adaptation: Coastal Erosion and Flooding; UNEP Riso Centre on Energy, Climate and Sustainable Development: Roskilde, Denmark, 2010; ISBN 978-87-550-3855-4.

36. GHD-GTC Joint Venture. Recommendations for Hazard Mitigation for the Seawall Earthquake Vulnerability Study_Phase 3 Draft Report; Port of San Francisco: San Francisco, CA, USA, 2016; p. 154.

37. Huang, H.; Tang, Y. Residential land use regulation and the US housing price cycle between 2000 and 2009. J. Urban Econ. 2012, 71, 93-99. [CrossRef]

38. Mian, A.; Sufi, A. The Consequences of Mortgage Credit Expansion: Evidence from the U.S. Mortgage Default Crisis. Q. J. Econ. 2009, 124, 1449-1496. [CrossRef]

39. Williams, S.; Ismail, N. Climate Change, Coastal Vulnerability and the Need for Adaptation Alternatives: Planning and Design Examples from Egypt and the USA. J. Mar. Sci. Eng. 2015, 3, 591-606. [CrossRef]

40. Hillen, M.; Jonkman, S.; Kanning, W.; Kok, M.; Geldenhuys, M.; Stive, M. Coastal Defense Cost Estimates; Delft University of Technology, Royal Haskoning: Delft, The Netherlands, 2010; ISSN 0169-6548.

41. Jonkman, S.N.; Kok, M.; van Ledden, M.; Vrijling, J.K. Risk-based design of flood defence systems: A preliminary analysis of the optimal protection level for the New Orleans metropolitan area. J. Flood Risk Manag. 2009, 2, 170-181. [CrossRef]

42. Di Baldassarre, G.; Viglione, A.; Carr, G.; Kuil, L.; Salinas, J.L.; Blöschl, G. Socio-hydrology: Conceptualising human-flood interactions. Hydrol. Earth Syst. Sci. 2013, 17, 3295-3303. [CrossRef]

43. Restemeyer, B.; Woltjer, J.; van den Brink, M. A strategy-based framework for assessing the flood resilience of cities-A Hamburg case study. Plan. Theory Pract. 2015, 16, 45-62. [CrossRef]

44. Elkema, M.; Wang, Z.B.; Stive, M.J.F. Impact of Back-Barrier Dams on the Development of the Ebb-Tidal Delta of the Eastern Scheldt. J. Coast. Res. 2012, 28, 1591-1605. [CrossRef]

45. Giannico, G.R.; Souder, J.A. Tide Gates in the Pacific Northwest: Operation, Types, and Environmental Effects; Oregon Sea Grant, Oregon State University: Corvallis, OR, USA, 2005; Volume 5.

46. Gordon, J.; Arbeider, M.; Scott, D.; Wilson, S.M.; Moore, J.W. When the Tides Don't Turn: Floodgates and Hypoxic Zones in the Lower Fraser River, British Columbia, Canada. Estuar. Coasts 2015, 38, 2337-2344. [CrossRef]

47. Louters, T.; Mulder, J.P.; Postma, R.; Hallie, F.P. Changes in coastal morphological processes due to the closure of tidal inlets in the SW Netherlands. J. Coast. Res. 1991, 7, 635-652.

(C) 2017 by the authors. Licensee MDPI, Basel, Switzerland. This article is an open access article distributed under the terms and conditions of the Creative Commons Attribution (CC BY) license (http://creativecommons.org/licenses/by/4.0/). 